Nobuhiko Okamoto • Yasuhisa Toribe - Tohru Nakajima

Takeshi Okinaga · Kenji Kurosawa • Ikuya Nonaka

Osamu Shimokawa $\cdot$ Naomichi Matsumoto

\title{
A girl with 1p36 deletion syndrome and congenital fiber type disproportion myopathy
}

Received: March 4, 2002 / Accepted: July 7, 2002

\begin{abstract}
Chromosome 1p36 deletion syndrome is characterized by hypotonia, moderate to severe developmental and growth retardation, and characteristic craniofacial dysmorphism. Muscle hypotonia and delayed motor development are almost constant features of the syndrome. We report a 4-year-old Japanese girl with 1p36 deletion syndrome whose muscle pathology showed congenital fiber type disproportion (CFTD) myopathy. This is the first case report of 1p36 deletion associated with CFTD. This association may indicate that one of the CFTD loci is located at 1p36. Ski proto-oncogene $-/-$ mice have phenotypes that resemble some of the features observed in patients with 1 p36 deletion syndrome. Because fluorescent in situ
\end{abstract}

N. Okamoto $(\square)$

Department of Planning and Research, Osaka Medical Center and Research Institute for Maternal and Child Health, 840 Murodo-cho, Izumi, Osaka 594-1101, Japan

Tel. +81-725-56-1220; Fax +81-725-56-5682

e-mail: YB9N-OKMT@asahi-net.or.jp

Y. Toribe

Division of Pediatric Neurology, Osaka Medical Center and

Research Institute for Maternal and Child Health, Osaka, Japan

T. Nakajima

Division of Pediatric Cardiology, Osaka Medical Center and

Research Institute for Maternal and Child Health, Osaka, Japan

T. Okinaga

Department of Pediatrics, Osaka University School of Medicine, Osaka, Japan

K. Kurosawa

Division of Medical Genetics, Kanagawa Children's Medical Center, Yokohama, Japan

I. Nonaka

Department of Ultrastructural Research, National Institute of Neuroscience, National Center of Neurology and Psychiatry, Tokyo, Japan

O. Shimokawa

Kyushu Medical Science Nagasaki Laboratory, Nagasaki, Japan

N. Matsumoto

Department of Human Genetics, Nagasaki University School of Medicine, Nagasaki, Japan

N. Matsumoto

CREST, Science and Technology Corporation, Kawaguchi, Japan hybridization analysis revealed that the human $S K I$ gene is deleted in our patient, some genes in 1p36, including $S K I$ proto-oncogene, may be involved in muscle hypotonia and delayed motor development in this syndrome.

Key words 1 p36 deletion syndrome - Submicroscopic deletion - Congenital fiber type disproportion myopathy • Cardiomyopathy $\cdot S K I$ proto-oncogene

\section{Introduction}

Chromosome 1p36 deletion syndrome is a recently recognized, relatively common contiguous gene deletion syndrome, i.e., a genomic disorder. The prevalence of the syndrome is estimated to be $1 / 10,000$ newborns (Shapira et al. 1997). It is associated with muscle hypotonia and moderate to severe developmental delay, growth retardation, microcephaly, and craniofacial dysmorphism with a large anterior fontanelle, prominent forehead, deep-set eyes, flat nasal bridge and midface hypoplasia, ear asymmetry, and a pointed chin (Shapira et al. 1997; Slavotinek et al. 1999). Minor cardiac malformations, dilated cardiomyopathy, epileptic seizures, and ventricular dilatation are additional findings. Muscle hypotonia and delayed motor development are almost constant features of the syndrome. Genes distal to 1 p36 are deleted and may be associated with various manifestations of the syndrome. The extent of the deletion is variable with the shortest region of overlap for deletion; however, the causative genes for developmental abnormalities have not been identified (Wu et al. 1999). Colmenares et al. (2002) found that SKI proto-oncogene may contribute to some of the phenotypes common in 1p36 deletion syndrome, particularly to facial clefting.

We report a patient with 1 p36 deletion syndrome whose muscle pathology showed congenital fiber type disproportion (CFTD). CFTD myopathy is characterized by type 1 fibers smaller than type 2 fibers (Brooke and Engel 1969). The molecular basis of CFTD is unknown. Chromosome 1p36 deletion and CFTD seen together in a patient may 
indicate that one of the genes located at 1pter-36 is associated with the pathogenesis of CFTD.

\section{Clinical report}

The patient was a 4-year-old Japanese girl born to nonconsanguineous healthy parents who were both 32 years old. Birth weight of the patient was $2890 \mathrm{~g}$ at 41 weeks of gestation. Apgar scores were 9 at $1 \mathrm{~min}$ and 10 at $5 \mathrm{~min}$, respectively. At 9 days of age, she was transferred to a hospital because of abnormal ocular movement with vertical nystagmus. She was difficult to feed. Right congenital hip dislocation was noted, which later necessitated surgical treatment. Conventional G-banded chromosome analysis showed a normal 46,XX karyotype. At 7 months of age, she was introduced to our hospital because of dilated cardiomyopathy. She had dysmorphic features that included microcephalus, prominent forehead, widely patent anterior fontanelle, hypertelorism, deep-set eyes, midface hypoplasia, flat nasal bridge, nasal deformation with minute cleft lip in the right side, low-set ears, down slanting oral corners, pointed chin, and generalized hypotonia. Deep tendon reflex was diminished. At 10 months of age, she developed repeated nonepileptic apneic episodes that sometimes required resuscitation. Home oxygen therapy was effective to relieve apnea. She started to crawl at 18 months, and sat at 21 months. Serum creatine kinase (CK) levels were slightly or mildly elevated ( $\max 526 \mathrm{U} / \mathrm{l}$; normal range, 30-150 U/l). Laboratory tests for various metabolic disorders were unremarkable. Electroencephalography showed no epileptic findings. Magnetic resonance imaging of the brain showed unremarkable change. At two years of age, electromyography (EMG) showed a myogenic change. Muscle biopsy of the left biceps muscle was done to evaluate the pathogenesis of hypotonia (Fig. 1). The diagnosis of CFTD was made; however, it was not enough to explain her dysmorphic features and severe developmental delay. At 4 years of age, her weight was $13.8 \mathrm{~kg}(-0.9 \mathrm{SD})$, length $95.3 \mathrm{~cm}(-1.1$ SD) and head circumference $49.0 \mathrm{~cm}(-0.9 \mathrm{SD})$. Dilated cardiomyopathy was still remarkable (Fig. 2). Her hypotonia continued and she could stand with support. She could speak no meaningful words. Her clinical manifestations were consistent with 1 p36 deletion syndrome. Subsequent analysis by fluorescent in situ hybridization (FISH) using a distal $1 \mathrm{p}$ probe (D1Z2) demonstrated a deletion at 1p36.3pter. Her karyotype was thus 46,XX.ish del(1)(p36.3) (D1Z2-). FISH analysis with a SKI-containing bacterial artificial chromosome (BAC) clone (CTD-2245C8) confirmed that $S K I$ was also deleted (Fig. 3). In further studies, the extent of the deletion was estimated to be smaller than $3 \mathrm{Mb}$ (Table 1). Karyotypes of her parents were normal.

\section{Discussion}

Clinical features observed in the girl included severe developmental delay, generalized hypotonia, and dysmorphic

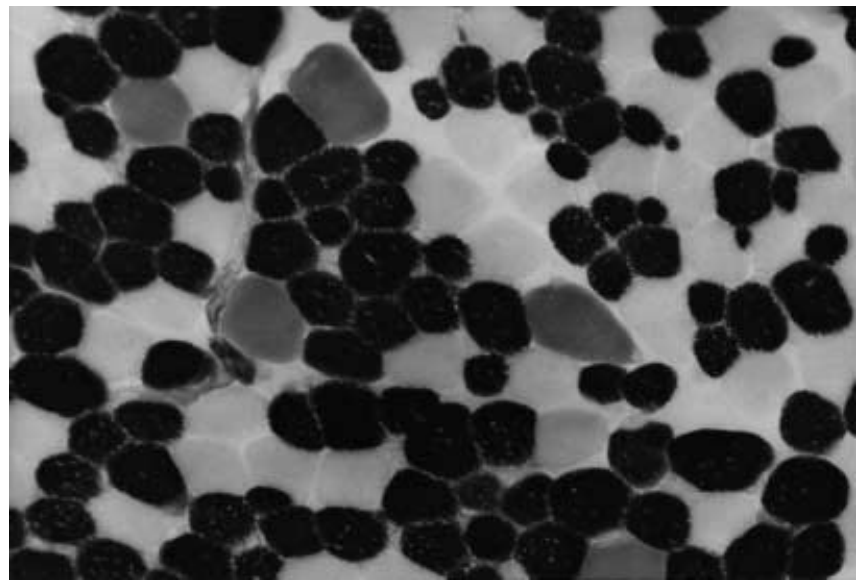

Fig. 1. Muscle histology of adenosine triphosphatase with preincubation at $\mathrm{pH}$ 4.6. Type 1 (dark) fibers are predominant (63\%) and significantly hypotrophic as compared with type 2A (light) and type 2B (intermediate) fibers. Type 2B fibers are decreased in number and deficient in some fascicles. Modified Gomori-trichrome and a battery of histochemical methods excluded the evidence of a dystrophic or metabolic myopathy

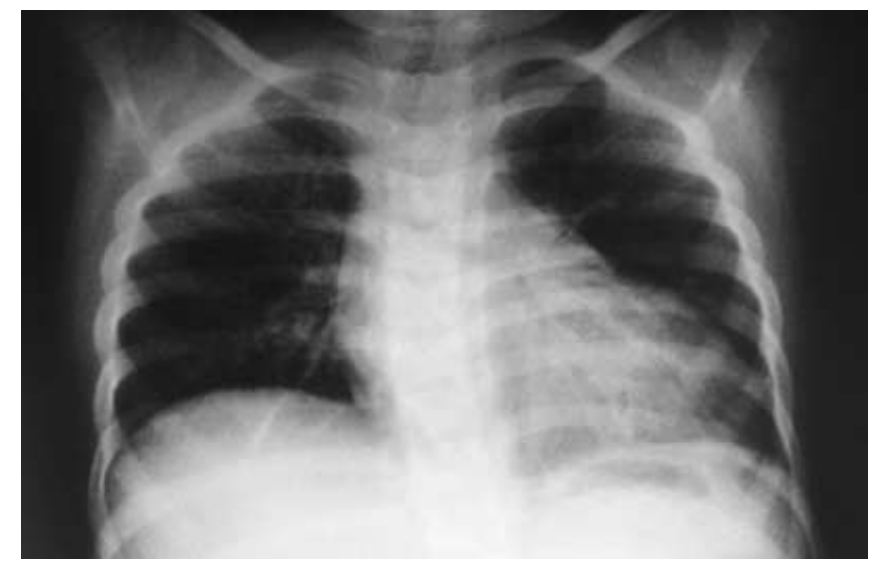

Fig. 2. Chest X-ray showing dilated cardiomyopathy

Table 1. Deleted and nondeleted regions in the patient as detected by FISH using probes at the distal end of $1 \mathrm{p}$

\begin{tabular}{llll}
\hline Location & Gene & Probe & $\begin{array}{l}\text { Presence }(+) \\
\text { or absence }(-) \\
\text { of FISH signal }\end{array}$ \\
\hline 1pter & & GC-232B23 & - \\
& & RP11-304C7 & - \\
& RP11-316I7 & - \\
& DVL1 & & \\
& CDC2L1 & & \\
& GNB1 & D1Z2 & - \\
$1.3 \mathrm{Mb}$ & SKI & CTD-2245C8 & - \\
& & RP11-46F15 & + \\
& & RP11-151F10 & + \\
$3 \mathrm{Mb}$ & RBR & PAC-785P20 & + \\
$5 \mathrm{Mb}$ & KCNAB2 & & + \\
$6.5 \mathrm{Mb}$ & & RP11-60J11 & + \\
cen & & & + \\
\hline
\end{tabular}

FISH, Fluorescent in situ hybridization 


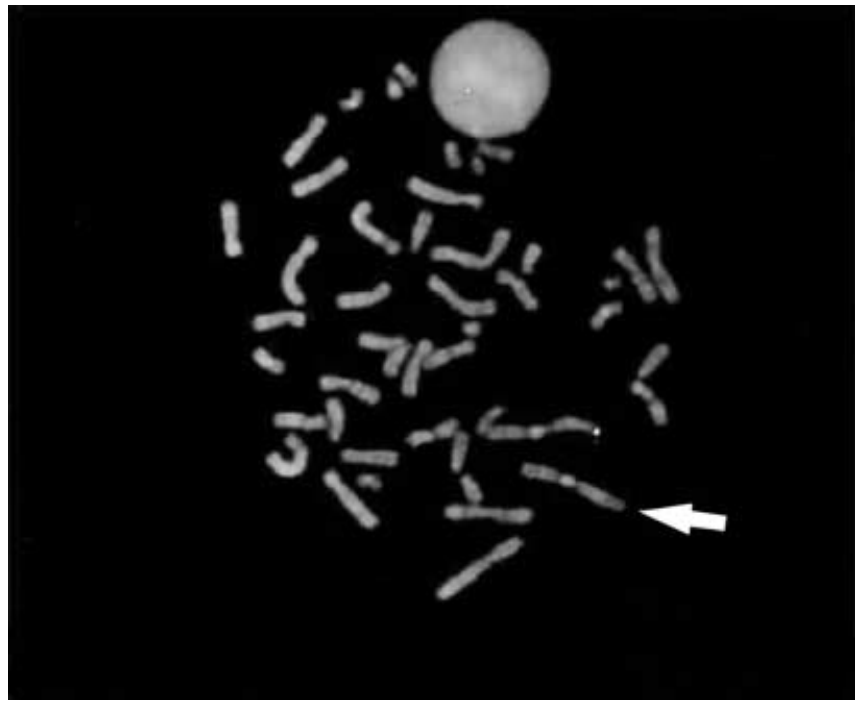

Fig. 3. Fluorescent in situ hybridization using a $S K I$ containing bacterial artificial chromosome (BAC) clone, CTD-2245C8. Arrow indicates deletion of $S K I$ on an abnormal chromosome 1, although $S K I$ signal appears on normal chromosome 1

features, all of which are typical for 1 p36 deletion syndrome. The association of 1 p36 deletion with CFTD has hitherto been reported. The genetic basis of CFTD remains unclear. Additionally, type 1 fiber atrophy is a common finding in childhood neuromuscular disorders, especially congenital myopathies (Imoto and Nonaka 2001). Because both autosomal dominant and recessive types of CFTD have been reported, it is believed to be genetically heterogeneous. Jaffe et al. (1998) reported two siblings affected with congenital progressive severe myopathy transmitted by an autosomal recessive mode. Muscle biopsy revealed fiber type disproportion with no other histological abnormalities, confirming the diagnosis of CFTD. Gerdes et al. (1994) reported a patient with myopathy and CFTD present at birth with arthrogryposis multiplex congenita, dislocation of the hips, and mild scoliosis. In this patient, a balanced chromosomal translocation $\mathrm{t}(10 ; 17)(\mathrm{p} 11.2 ; \mathrm{q} 25)$, transmitted by a clinically healthy mother, who nevertheless showed discrete signs of myopathy, was demonstrated. Gerdes et al. (1994) suggested that CFTD in the family may be dominantly inherited with variable expressivity and that either of the translocation breakpoints may harbor a candidate gene region. There are no further studies on the genetic mapping of CFTD. The number of reported pedigrees with CFTD is too small for linkage analysis.

Many genes are deleted in patients with 1p36 deletion syndrome. The neuroblastoma suppressor genes have been mapped to this region (White et al. 1995). Phenotype/ genotype correlation and refinements of critical regions delineated specific areas for the causative genes (Wu et al. 1999). For example, hemizygosity of $K C N A B 2$ is a significant risk factor for severe epilepsy (Heilstedt et al. 2001). Myopathy in our patient may be explained by haploinsufficiency of the putative causative genes or unmasking of certain recessive alleles. So far, several genes at 1p36 are known to be associated with muscle development. Micro- scopic analysis of the skeletal muscle from $\operatorname{Pax} 7(-/-)$ mice showed complete absence of satellite cells, markedly decreased muscle mass, and reduced fiber caliber (Seale et al. 2000). The human $P A X 7$ is assigned to $1 \mathrm{p} 36.2-36$ (Stapleton et al. 1993). Deletion of $P A X 7$ was excluded in our patient by FISH analysis with a BAC clone, RPCI-11 330C5 (data not shown). Human DVL1 is mapped to $1 \mathrm{p} 36.3$ and is widely expressed in fetal and adult tissues, including the brain, lung, kidney, skeletal muscle, and heart. DVL1 is deleted in some 1p36 deletion patients (Shapira et al. 1997; Bedell et al. 1996; Pizzuti et al. 1996). However, Dvlldeficient mice are viable, fertile, and structurally normal (Lijam et al. 1997). Human $A G R I N$ is mapped to 1pter-p36. Agrin is a component of the synaptic basal lamina that induces the clustering (aggregation) of acetylcholine receptors on cultured muscle fibers. Gautam et al. (1996) generated knockout mice deficient for agrin and showed that neuromuscular development was severely disturbed. Homozygous mutant mice died in utero or were stillborn. Gautam et al. (1996) reported that conventional histological analysis failed to detect gross abnormalities in any tissues.

The Ski proto-oncogene has been implicated in the control of cell growth and skeletal muscle differentiation. Sutrave et al. (1990) showed that overexpression of $S k i$ in skeletal muscles of transgenic mice leads to selective hypertrophy of type 2 fast fibers. In particular, type 2B fibers showed remarkable hypertrophy. Berk et al. (1997) disrupted the mouse $S k i$ gene, and $S k i(-/-)$ mice showed perinatal lethality, resulting from exencephaly and a dramatic reduction in skeletal muscle mass, consistent with a defect in expansion of a myogenic precursor population. Colmenares et al. (2002) showed that $\operatorname{Ski}(-/-)$ mice in the $\mathrm{C} 57 \mathrm{BL} / \mathrm{J}$ background showed midline facial clefting, depressed nasal bridge, eye abnormalities, skeletal muscle defects, and digit abnormalities. The phenotype in these mice resembles some of the features observed in patients with 1p36 deletion syndrome. Colmenares et al. (2002) found that human $S K I$ was deleted in patients with $1 \mathrm{p} 36$ deletion syndrome, and suggested that $S K I$ may contribute to some of the phenotypes common in the syndrome. Our patient showed significantly hypotrophic but predominant type 1 fibers and deficiency of type 2B fibers in some fascicles. Gene dosage effect of SKI may explain selective hypertrophy of type $2 \mathrm{~B}$ fibers in transgenic mice, deficiency of type 2B fibers in our (hemizygous) patient, and dramatic reduction of skeletal muscle mass in $\operatorname{Ski}(-/-)$ (nullizygous) mice. Although fiber-type specific abnormalities were not described in $S k i(+/-)$ and $(-/-)$ mice, we suspect that the $S K I$ deletion may be related to CFTD in our patient. Some of the other 1p36 deletion patients, especially those with severe hypotonia, may have muscle abnormalities. Because the serum CK level is not always high in such a patient, screening by EMG and confirmation by muscle biopsy are recommended. CFTD patients with mental retardation, dysmorphic features, and multiple anomalies should be investigated for $1 \mathrm{p} 36$ deletion.

Our patient and four other patients with $1 \mathrm{p} 36$ deletion were reported to have infantile cardiomyopathy (KepplerNoreuil et al. 1995; Slavotinek et al. 1999). Metabolic disor- 
ders for cardiomyopathy were excluded. A combination of cardiomyopathy and CFTD has been described (Banwell et al. 1999), whereas cardiac abnormalities were not described in $S k i(-/-)$ mice. It remains to be investigated whether cardiomyopathy is a component of $1 \mathrm{p} 36$ deletion syndrome or is associated with CFTD.

\section{References}

Banwell BL, Becker LE, Jay V, Taylor GP, Vajsar J (1999) Cardiac manifestations of congenital fiber-type disproportion myopathy. J Child Neurol 14:83-87

Bedell JA, Wagner-McPherson CB, Bengtsson U, Handa K, Dumars KW, Marsh JL, Smith M, McPherson JD (1996) A 1p deletion syndrome patient is hemizygous for a human homologue of the Drosophila dishevelled gene. Am J Hum Genet 59:A298

Berk M, Desai SY, Heyman HC, Colmenares C (1997) Mice lacking the ski proto-oncogene have defects in neurulation, craniofacial, patterning, and skeletal muscle development. Genes Dev 11:20292039

Brooke MH, Engel WK (1969) The histographic analysis of human muscle biopsies with regard to fibre types. IV. Children's biopsies. Neurology 19:591-605

Colmenares C, Heilstedt HA, Shaffer LG, Schwartz S, Berk M, Murray JC, Stavnezer E (2002) Loss of the SKI proto-oncogene in individuals affected with $1 \mathrm{p} 36$ deletion syndrome is predicted by straindependent defects in Ski -/- mice. Nat Genet 30:106-109

Gautam M, Noakes PG, Moscoso L, Rupp F, Scheller RH, Merlie JP, Sanes JR (1996) Defective neuromuscular synaptogenesis in agrindeficient mutant mice. Cell 85:525-535

Gerdes AM, Petersen MB, Schroder HD, Wulff K, Brondum-Nielsen K (1994) Congenital myopathy with fiber type disproportion: a family with a chromosomal translocation $\mathrm{t}(10 ; 17)$ may indicate candidate gene regions. Clin Genet 45:11-16

Heilstedt HA, Burgess DL, Anderson AE, Chedrawi A, Tharp B, Lee O, Kashork CD, Starkey DE, Wu YQ, Noebels JL, Shaffer LG, Shapira SK (2001) Loss of the potassium channel beta-subunit gene, $K C N A B 2$, is associated with epilepsy in patients with $1 \mathrm{p} 36$ deletion syndrome. Epilepsia 42:1103-1111
Imoto C, Nonaka I (2001) The significance of type 1 fiber atrophy (hypotrophy) in childhood neuromuscular disorders. Brain Dev 23:298-302

Jaffe M, Shapira J, Borochowitz Z (1998) Familial congenital fiber type disproportion (CFTD) with an autosomal recessive inheritance. Clin Genet 33:33-37

Keppler-Noreuil KM, Carroll AJ, Finley WH, Rutledge SL (1995) Chromosome $1 \mathrm{p}$ terminal deletion: report of new findings and confirmation of two characteristic phenotypes. J Med Genet 32:619622

Lijam N, Paylor R, McDonald MP, Crawley JN, Deng C-X, Herrup K, Stevens KE, Maccaferri G, McBain CJ, Sussman DJ, WynshawBoris A (1997) Social interaction and sensorimotor gating abnormalities in mice lacking Dvl1. Cell 90:895-905

Pizzuti A, Amati F, Calabrese G, Mari A, Colosimo A, Silani V, Giardino L, Ratti A, Penso D, Calza L, Palka G, Scarlato G, Novelli G, Dallapicolla B (1996) cDNA characterization and chromosomal mapping of two human homologs of the Drosophila dishevelled polarity gene. Hum Mol Genet 5:953-958

Seale P, Sabourin LA, Girgis-Gabardo A, Mansouri A, Gruss P, Rudnicki MA (2000) Pax7 is required for the specification of myogenic satellite cells. Cell 102:777-786

Shapira SK, McCaskill C, Northrup H, Spikes AS, Elder FF, Sutton VR, Korenberg JR, Greenberg F, Shaffer LG (1997) Chromosome 1p36 deletions: the clinical phenotype and molecular characterization of a common newly delineated syndrome. Am J Hum Genet 61:642-650

Slavotinek A, Shaffer LG, Shapira SK (1999) Monosomy 1p36. J Med Genet 36:657-663

Stapleton P, Weith A, Urbanek P, Kozmik Z, Busslinger M (1993) Chromosomal localization of seven PAX genes and cloning of a novel family member, PAX-9. Nat Genet 3:292-298

Sutrave P, Kelly AM, Hughes SH (1990) Ski can cause selective growth of skeletal muscle in transgenic mice. Genes Dev 4:14621472

White PS, Maris JM, Beltinger C, Sulman E, Marshall HN, Fujimori M, Kaufman BA, Biegel JA, Allen C, Hilliard C, Valentine MB, Look AT, Enomoto H, Sakiyama S, Brodeur GM (1995) A region of consistent deletion in neuroblastoma maps within human chromosome 1p36.2-36.3. Proc Natl Acad Sci USA 92:5520-5524

Wu YQ, Heilstedt HA, Bedell JA, May KM, Starkey DE, McPherson JD, Shapira SK, Shaffer LG (1999) Molecular refinement of the 1p36 deletion syndrome reveals size diversity and a preponderance of maternally derived deletions. Hum Mol Genet 8:313-321 